\title{
Mapeamento da deposição irregular dos resíduos provenientes da construção civil na cidade de Mossoró-RN
}

\section{Mapping of irregular dumping of solid waste from construction industry at Mossoró-RN, Brazil}

\author{
Giordanio Bruno Silva Oliveira ${ }^{1}$, Ellen Ramona de Almeida Correia Brito ${ }^{2}$, Luan Alves Lima ${ }^{3}$, Leonardo Vieira de Sousa ${ }^{4}$, \\ Francisco de Assis de Oliveira
}

Resumo: A construção civil tem sido considerada uma das mais importantes atividades para o desenvolvimento da sociedade, porém é uma atividade que causa impactos ambientais, pois utiliza recursos naturais, modifica o meio ambiente e gera um grande volume de resíduos. Nota-se que as atividades ligadas à construção civil no município de Mossoró-RN, são responsáveis por gerar uma quantidade considerável de resíduos de construção civil (RCC), que na maioria das vezes, são depositados em locais irregulares, por não haver na cidade um local específico para esse fim. Esses resíduos constituem um grave problema, tanto para o meio ambiente quanto para qualidade de vida da população. A pesquisa foi realizada com o objetivo de mapear áreas de depósito irregular de resíduos provenientes da construção civil na cidade de Mossoró-RN. Foi realizada a demarcação dos pontos de acordo com a localização do despejo dos resíduos, com a finalidade de identificar e indicar sua localização dentro da zona urbana de Mossoró-RN. No presente estudo, foi possível identificar 11 pontos de deposição irregular de resíduos provenientes da construção civil, espalhados em diferentes locais da cidade, alguns situando-se próximo de áreas residenciais, o que caracteriza sérios riscos à saúde pública, e outros dispostos próximos de cursos d'água, o que provoca degradação do meio ambiente.

Palavras-chave: Sustentabilidade, Impacto Ambiental, Entulho, Construção Civil.

\begin{abstract}
Construction industry has been considered one of the most important activities regarding to society development, however it causes environmental impacts, because it uses natural resources, modifies the environment and generate a huge amount of waste. It was observed that in Mossoró, RN, Brazil, a large amount of construction waste is often deposed in unauthorized sites because the municipality does not provide a specific site for this purpose. Such waste is a serious problem for the environment and for the people's quality of living. In this context a research was carried out with the objective of mapping sites of non authorized deposition of construction waste in the city of Mossoró, RN, Brazil. With this intent, points were georeferenced according to the location of deposition of waste, with the objective of identifying and indicating its location inside the urban zone of the city. At the end of the study were identified eleven sites of unauthorized deposition of construction waste, all over the city, some of which were located near residential areas, what poses a serious hazard to public health, while other sites were near water streams, what promote environmental degradation.
\end{abstract}

Key words: Sustainability, Environmental Impact, Rubble, Construction.

\footnotetext{
*Autor para correspondência

Recebido para publicação em 15/05/2016; aprovado em 28/07/2016

${ }^{1}$ Graduando em Agronomia, Universidade Federal Rural do Semi-Árido, Mossoró-RN; (84) 996672908, E-mail: giordaniobruno1 @ gmail.com

${ }^{2}$ Graduada em Engenharia Civil, Universidade Federal Rural do Semi-Árido, E-mail: ellen_ramona@hotmail.com

${ }^{3}$ Graduado em Agronomia, Universidade Federal Rural do Semi-Árido, E-mail: luanefa2@ yahoo.com.br

${ }^{4}$ Graduando em Agronomia, Universidade Federal Rural do Semi-Árido, E-mail: leoigt@ hotmail.com

${ }^{5}$ Doutor em Irrigação e Drenagem pela Escola Superior de Agricultura Luiz de Queiroz, prof. Adjunto da UFERSA, E-mail: thikaoamigao@ufersa.edu.br
} 


\section{INTRODUÇÃO}

A construção civil destaca-se como uma das mais importantes para o desenvolvimento da sociedade, no entanto, por utilizar recursos naturais, torna-se inevitável modificar o meio e gerar grande volume de resíduos, resultando em diversos impactos ambientais. Dessa forma, nas últimas décadas vem aumentando a preocupação de órgãos ambientais quanto à disposição final dos resíduos gerados por esta atividade (TESSARO, 2012).

Os resíduos da construção civil são popularmente conhecidos por entulhos e tecnicamente são definidos como todo rejeito de material utilizado na execução de etapas de obras em atividades de construção civil, podendo ser oriundas de obras de infraestrutura, demolições, reformas, restaurações, reparos, construções novas, etc. tais como um conjunto de fragmentos ou restos de pedregulhos, areias, materiais cerâmicos, argamassa, aço, madeira, etc. (GAEDE, 2008).

De acordo com o SINDUSCON/RN (2011), o entulho de construção civil representa, hoje, um dos maiores problemas para o saneamento público municipal, principalmente nas grandes cidades brasileiras. Estima-se que as grandes e médias cidades brasileiras geram uma massa de entulho que pode chegar a $40 \%$ do total dos resíduos sólidos urbanos produzidos.

De fato, nota-se que as atividades ligadas à construção civil no município de Mossoró-RN, são responsáveis por gerar uma quantidade considerável de resíduos de construção civil (RCC).

Esses resíduos constituem um grave problema, tanto para o meio ambiente quanto para qualidade de vida da população, agindo de forma direta na poluição e degradação de áreas urbanas, reprodução e desenvolvimento de vetores de doenças, abrigo para ratos, moscas e outros insetos, além de afetar a paisagem urbana e o trafego de veículos.

Atualmente é dada maior atenção por políticas públicas que abordam os resíduos gerados pelo setor da construção civil no país, abrindo assim, discussões a respeito das questões ambientais.

A Resolução $n^{\circ}$ 307/2002 do Conselho Nacional de Meio Ambiente (CONAMA), define responsabilidades do poder público e dos agentes privados quanto aos resíduos da construção civil e torna obrigatória a adoção de planos integrados de gerenciamento nos municípios, além de projetos de gerenciamento dos resíduos gerados nos canteiros de obra, criando assim, vários instrumentos que contribuem para o desenvolvimento sustentável e a redução da degradação do ambiente.

A pesquisa foi realizada com o objetivo de mapear áreas de depósito irregular de resíduos provenientes da construção civil na cidade de Mossoró-RN.

\section{MATERIAL E MÉTODOS}

O estudo foi desenvolvido no município de Mossoró, $\mathrm{RN}$, situado na mesorregião do oeste potiguar (Figura 1), à $278 \mathrm{~km}$ de Natal, a capital do estado, ocupando uma área de $2.099,33 \mathrm{~km}^{2}$, com uma população estimada em 288.162 (IBGE, 2015).

O município é visto como importante cenário para a análise, por apresentar um grande desenvolvimento no setor de construção civil, com elevado número de obras, e consequentemente grande produção de resíduos.

Inicialmente, realizou-se uma pesquisa bibliográfica através de fontes de dados disponíveis no meio digital, impresso e na rede mundial de computadores. Mediante isso, foi possível contextualizar os problemas de impactos ambientais decorrentes da deposição irregular dos resíduos sólidos em áreas urbanas.

Foi realizada a demarcação dos pontos de acordo com a localização do despejo dos resíduos, com a finalidade de identificar e quantifica-los dentro da zona urbana de MossoróRN. O levantamento foi realizado no período de 07 a 09 de fevereiro de 2014 e os dados foram coletados com o auxílio de um receptor móvel de sinal do Global Positioning System (GPS), em português Sistema de Posicionamento Global. As coordenadas geográficas foram escolhidas aleatoriamente, porém buscou-se abranger toda a cidade.

Após a coleta, os dados foram transferidos para um computador com auxílio do programa TrackMaker, comumente empregado para a criação de mapas detalhados. Em seguida os pontos foram sincronizados com o mapa da região.

Figura 1. Localização geográfica do município de MossoróRN, 2015.

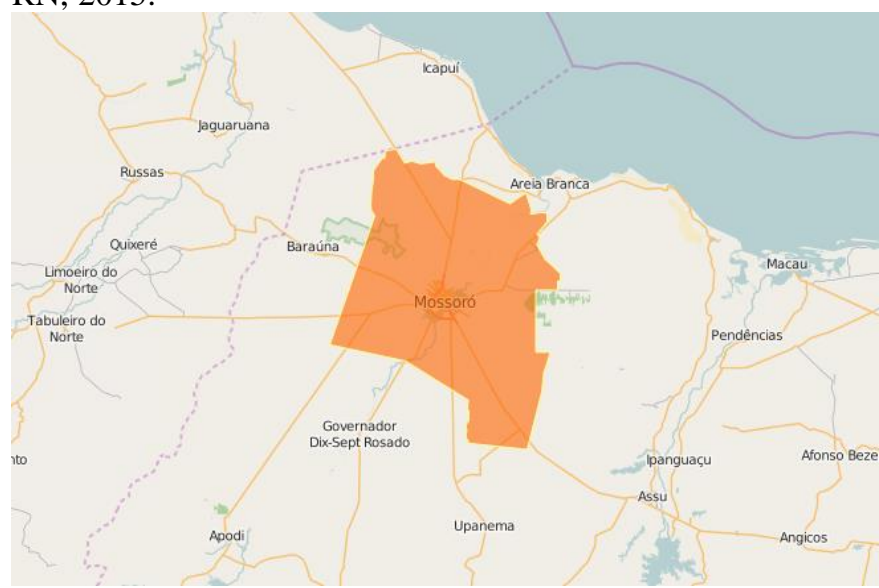

Fonte: IBGE

\section{RESULTADOS E DISCUSSÃO}

A determinação da quantidade e dos locaisde deposição irregular dos RCC, gerados nas cidades, é de grande importância, visto que possibilita a elaboração de estratégias e alternativas para destinação final desses resíduos em locais adequados.

Segundo a ABRELPE (2014), cerca de 45 milhões de toneladas de Resíduos de Construção e Demolição (RCD) foram geradas em 2014, no entanto, a quantidade total desses resíduos é ainda maior, uma vez que os municípios, via de regra, coletam apenas os resíduos de obras sob sua responsabilidade e os lançados nos logradouros públicos.

Em Mossoró, de acordo com Silva (2015), a coleta de RCC é realizada diariamente seguindo percurso feito pela prefeitura ou solicitado pela população. A média mensal de RCC coletados é de 20.000 m³/mês.

Atualmente a área utilizada pela prefeitura de Mossoró$\mathrm{RN}$, para a disposição desses resíduos é o "lixão das Cajazeiras", que acaba sendo local inadequado, uma vez que o mesmo foi desativado em 2008, período em que a prefeitura 
cessou a disposição de resíduos sólidos domiciliares no local (MOSSORÓ, 2012).

Foram identificados 11 pontos de deposição irregular de resíduos provenientes da construção civil, espalhados em diferentes locais da cidade de Mossoró conforme mostrado na Tabela 1 .

Tabela 1-Coordenadas geográficas dos pontos críticos de deposição irregular de resíduos oriundos da construção civil na cidade de Mossoró-RN, 2014.

\begin{tabular}{|c|c|c|c|}
\hline \multirow{2}{*}{ Ponto } & \multirow{2}{*}{ Bairro } & \multicolumn{2}{|c|}{ Coordenadas } \\
\hline & & Latitude & Longitude \\
\hline 1 & Abolição & $5^{\circ} 9^{\prime} 15.01 " \mathrm{~S}$ & $37^{\circ} 22^{\prime} 16.45^{\prime \prime O}$ \\
\hline 2 & Abolição & $5^{\circ} 9^{\prime} 38.58^{\prime \prime} \mathrm{S}$ & $37^{\circ} 21^{\prime} 30.15^{\prime \prime O}$ \\
\hline 3 & Santo Antônio & $5^{\circ} 9^{\prime} 9.03 " \mathrm{~S}$ & $37^{\circ} 20^{\prime} 27.40^{\prime \prime} \mathrm{O}$ \\
\hline 4 & Barrocas/Passagem de Pedras & $5^{\circ} 9^{\prime} 25.18 " \mathrm{~S}$ & $37^{\circ} 18^{\prime} 51.33^{\prime \prime O}$ \\
\hline 5 & Barrocas/Passagem de Pedras & $5^{\circ} 9^{\prime} 51.84 " \mathrm{~S}$ & $37^{\circ} 19^{\prime} 6.05^{\prime \prime} \mathrm{O}$ \\
\hline 6 & Barrocas/Passagem de Pedras & $55^{\circ} 9^{\prime} 58.39^{\prime \prime} \mathrm{S}$ & $37^{\circ} 19^{\prime} 12.35^{\prime \prime} \mathrm{O}$ \\
\hline 7 & Barrocas/Passagem de Pedras & $5^{\circ} 10^{\prime} 29.01 " \mathrm{~S}$ & $37^{\circ} 19^{\prime} 42.83^{\prime \prime O}$ \\
\hline 8 & Pintos & $5^{\circ} 11^{\prime} 36.42^{\prime \prime S}$ & $37^{\circ} 18^{\prime} 56.64^{\prime \prime O}$ \\
\hline 9 & Vingt-Rosado & $5^{\circ} 12^{\prime} 18.11^{\prime \prime S}$ & $37^{\circ} 17^{\prime} 50.88^{\prime \prime O}$ \\
\hline 10 & Alto de São Manoel & $5^{\circ} 12^{\prime} 27.86^{\prime \prime S}$ & $37^{\circ} 20^{\prime} 26.69^{\prime \prime} \mathrm{O}$ \\
\hline 11 & Alagados & $5^{\circ} 12^{\prime} 51.39^{\prime \prime} \mathrm{S}$ & $37^{\circ} 20^{\prime} 45.74^{\prime \prime} \mathrm{O}$ \\
\hline
\end{tabular}

Constata-se que a região que apresenta maior número de pontos de deposição irregular de resíduos compreende o trecho Barrocas/Passagem de Pedras, com 4 pontos, seguido pelo bairro Abolição com 2 pontos, e os demais bairros com 1 ponto cada (Tabela 1).

Como no município ainda não existe um local exclusivo para descarte de RCC, é certo que as áreas de deposição irregular existentes se mantenham ou até mesmo aumentem seu número. Além disso, a falta de um local adequado para deposição dos resíduos, resultará em ações apenas corretivas, como realização de limpezas emergenciais dos pontos onde ocorrem deposições ilegais, e na ausência de soluções definitivas satisfatórias, o "lixão das cajazeiras", acaba se firmando como bota-fora não oficial, tornando rotineiras as limpezas emergenciais, o que não resolvem em nada a situação, pois no dia seguinte as mesmas áreas se tornam alvos para nova deposição ilegal.

Marques Neto (2005) assegura que, para amortizar o acondicionamento irregular dos resíduos, são necessárias instalações de pontos de recebimento de RCC em diferentes locais, para assim as empresas coletoras e os pequenos geradores descarregarem em locais apropriados.

No estudo foi possível constatar que alguns pontos encontram-se próximos a áreas residenciais, como é o caso dos pontos da região Vingt-Rosado e Pintos (Figura 2), o que acaba prejudicando o aspecto visual desses bairros, além de apresentar-se como risco a saúde para as pessoas que moram na localidade, já que tal pratica cria condições favoráveis ao aparecimento e desenvolvimento de vetores de doenças.

$\mathrm{Na}$ Figura 3 é possível visualizar que a deposição de resíduos de construção civil, tem ocorrido em conjunto com a de resíduos domésticos e de restos de animais, ato que parece ser prática comum de parte da população local, que assim o faz, mesmo contando com uma coleta regular dos resíduos domésticos por parte da prefeitura. Para evitar tais problemas faz-se necessário a conscientização da população, principalmente com Programas de Educação Ambiental.
Figura 2. Pontos de deposição irregular de RCC, Bairros Vingt-Rosado e Pintos. Mossoró- RN, 2014.

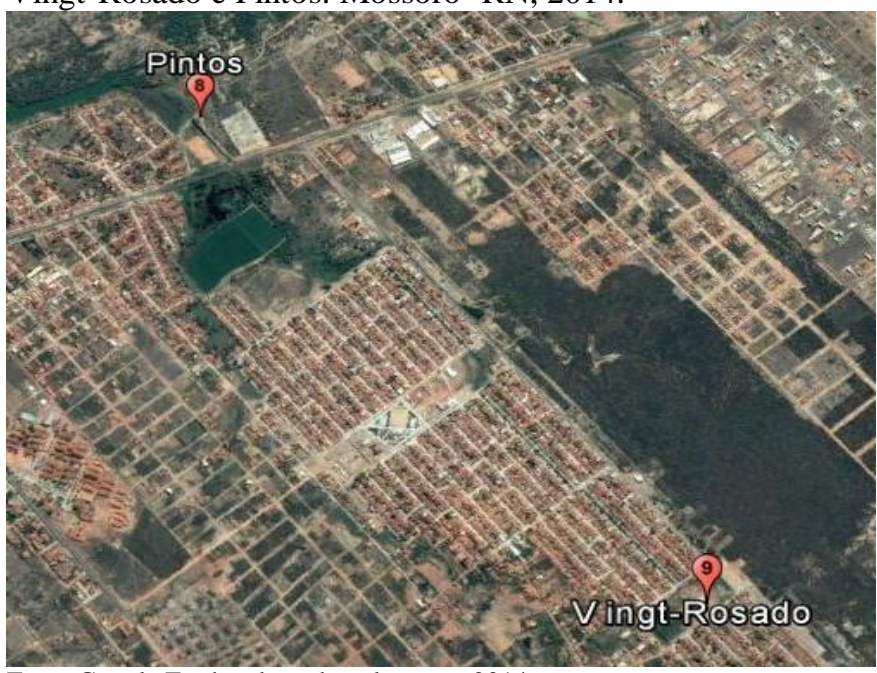

Fonte Google Earth, adaptado pelo autor, 2014.

Figura 3. Entulho misturado com resíduos domésticos. Mossoró- RN, 2014.

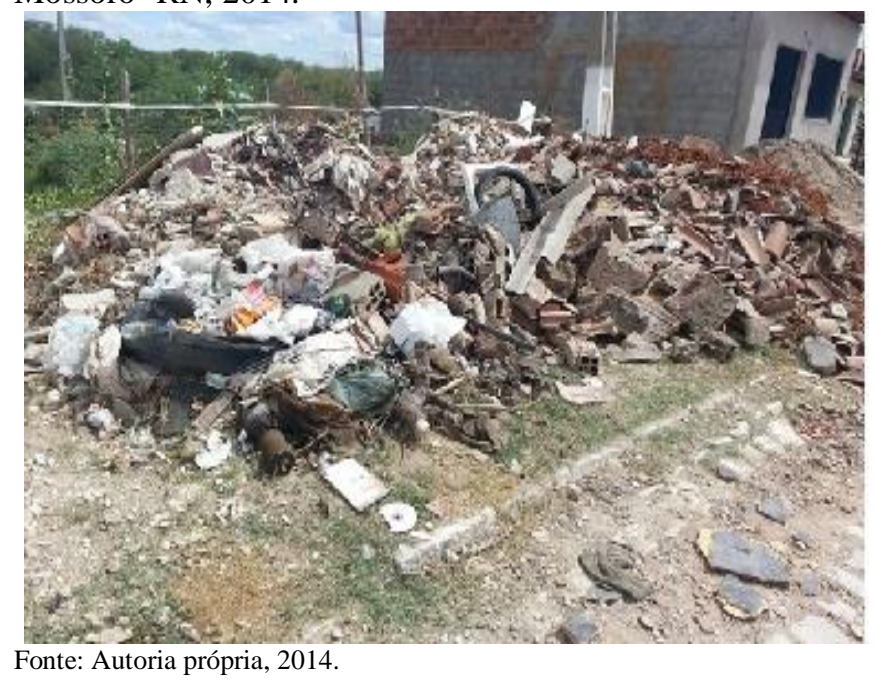


Dentre os locais visitados, os pontos irregulares compreendidos pela região Barrocas/Passagem de Pedras, Figura 4, são os que demandam maior atenção, por se localizarem próximo ao rio Apodi-Mossoró, os mesmos expõe elevado risco ambiental. No período chuvoso os resíduos podem vir a ser carreados para o curso d'água, podendo assim contaminá-lo.

É de competência do município, dirigir políticas públicas para o adequado manejo dos RCC na cidade, com o objetivo de providenciar o local de disposição final e fiscalizar a disposição em áreas não regulamentadas (MOURÃO, 2015).

Silva (2015) relata que a prefeitura municipal de Mossoró-RN, projeta conseguir licença de uma área próxima ao lixão das cajazeiras, para construção de uma estrutura física e transformar o local no Aterro de Inertes do município e consequentemente reduzir os impactos ambientais provenientes da deposição irregular em diversos pontos da cidade.

Na Figura 5 é possível visualizar o arranjo espacial de todos os pontos de deposição irregular, situados aos arredores da cidade.
Figura 4. Pontos de deposição irregular, Região Barrocas/Passagem das pedras. Mossoró-RN, 2014.

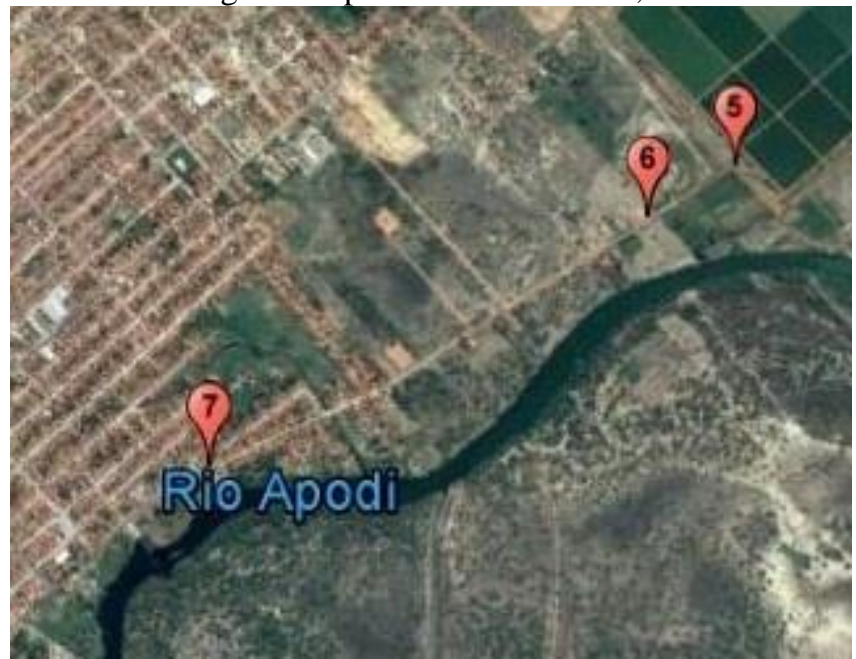

Fonte: Google Earth, adaptado pelo autor, 2014.

Figura 5. Localização dos pontos críticos de deposição irregular de resíduos oriundos da construção civil em Mossoró-RN.

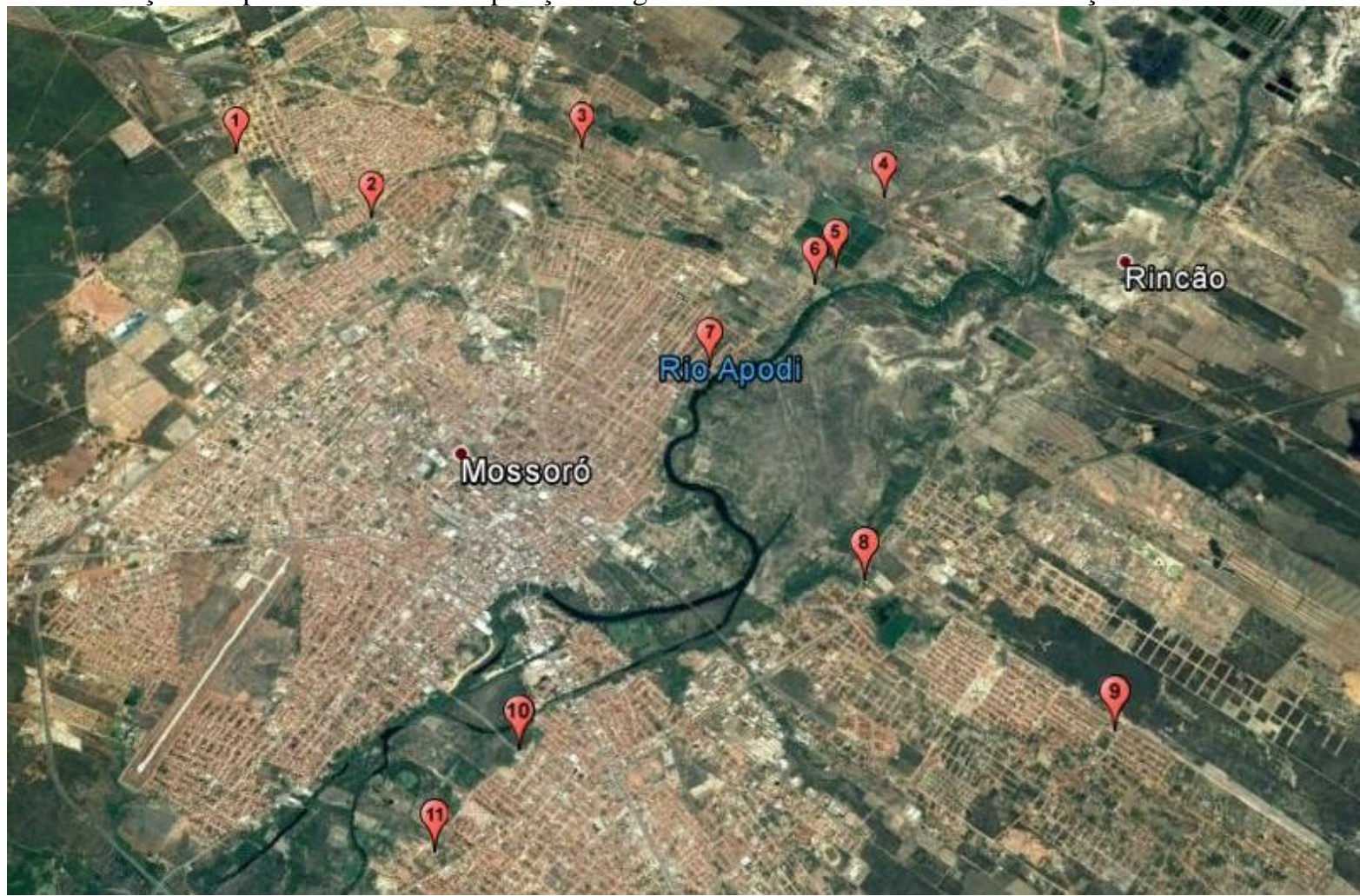

Fonte: Google Earth, adaptado pelo autor, 2014

\section{CONCLUSÕES}

Foi possível constatar que existem diversos pontos de deposição irregular de RCC em Mossoró, alguns situando-se próximo de áreas residenciais o que caracteriza sérios riscos à saúde pública, e outros dispostos próximos de cursos d'água, o que provoca degradação do meio ambiente. Este fato pode estar relacionado a diversos fatores, como a falta de consciência da população, o descaso por parte dos órgãos responsáveis pela fiscalização, falta de locais apropriados e estruturas adequadas para a deposição dos resíduos.

\section{REFERÊNCIAS}

ABELPRE - Associação Brasileira das Empresas de Limpeza Pública e Resíduos Especiais. Panorama dos resíduos no Brasil 2014. Disponível em:< http://www.abrelpe.org.br/Panorama/panorama2014.pdf>.

Acesso em: 02 jul. 2016.

CONAMA. Conselho nacional do meio ambiente. Resolução Conama $\mathrm{n}^{\circ}$ 300, de 20 de março de 2002. Disponível em: <http://www.mma.gov.br/port/conama/legislacao/conama_res _cons_2002_300>. Acesso em: 02 jul. 2016. 
GAEDE, L. P. F. Gestão dos resíduos da construção civil no município de Vitória-ES e normas existentes. Belo Horizonte, 2008.

IBGE. Instituto Brasileiro de Geografia e Estatística: Estimativa da População. 2015. Disponível em:<http://www.cidades.ibge.gov.br/xtras/temas.php?lang=\& codm un=240800\&idtema=130\&search=riogrande|estimativa-da-populacao-2015->. Acesso em: 01 jul. 2016.

MARQUES NETO, J. C. Gestão dos resíduos de construção e demolição no Brasil. São Carlos - SP: RiMa, p. 162. 2005.

MOURÃO, S. A.; ARAGÃO, V. R.; DAMASCENO, D. A. P. M. Diagnóstico da disposição dos resíduos sólidos da construção civil na cidade de Montes Claros, MG. Ciência e Natura, Santa Maria, v. 37 n.42, p. 251-261 jun. 2015.

MOSSORÓ (Município). Secretaria Municipal de Serviços Urbanos, Trânsito e Transportes Públicos. Plano de saneamento setorial: limpeza urbana e manejo dos resíduos sólidos. Mossoró, RN: Ziguia Engenharia, 2012. 140 p. Disponível

<http://www.prefeiturademossoro.com.br/planosaneamen to/planodemossoro.pdf>. Acesso em: 02 jul. 2016.

SILVA, A. L. B; MORAIS, P. A. R. Análise do gerenciamento dos resíduos sólidos urbanos no município de Mossoró-RN. VI Congresso Brasileiro de Gestão Ambiental. Porto Alegre/RS - $\quad 23 \quad$ a 26/11/2015.Disponívelem:<http://www.ibeas.org.br/congress o/Trabalhos2015/III- 04.pdf>. Acesso em: 03 jul. 2016.

SINDUSCON-RN, Sindicato da Indústria da Construção Civil do Rio Grande do Norte. 2011. Disponível em: <http://www.sindindustria.com.br/main.jsp?lumPageId=4028 4861E4C2A1D011E64343646 1942> Acesso em: 02 Jul. 2016.

TESSARO, A. B.; SÁ, J. S.; SCREMIN, L. B. Quantificação e classificação dos resíduos procedentes da construção civil e demolição no município de Pelotas, RS. Ambiente Construído, v. 12, n. 2, p. 121-130, 2012. 